\title{
Hardware and Software Integration of an Electrophoretic display on a smart meter
}

\author{
Sebastian Avram ${ }^{1}$, Cătălin Daniel Căleanu ${ }^{1}$, Radu Vasiư ${ }^{1}$,Andreea-Mirela Safta ${ }^{2}$,Horatiu \\ George Belei ${ }^{3}$, \\ ${ }^{1}$ Faculty of Electronics, Telecommunications and Information Technologies Politehnica University \\ of Timişoara, Timişoara, Romania \\ ${ }^{2}$ Honeywell, Timişoara, Romania \\ ${ }^{3}$ Frontier Silicon, Timişoara, Romania
}

\begin{abstract}
Electronic and smart electricity meters traditionally use as user interface liquid crystal displays due to low cost and proven technology. This paper presents the integration of a flexible electrophoretic display on a smart meter and the possible use cases of such a display. The two main benefit of EPD displays are image retention which can be used as read without power feature and lower power consumption compared to LCD for smart meters. The smart meters available on the market use batteries or super capacitors for the read without power feature and require each $20 \mathrm{~ms}$ tenths of $\mathrm{mA}$ to display information on the LCD.
\end{abstract}

\section{Introduction}

Electrophoretic displays (EPD) have been extensively studied in the 1970s [1], [2] and there are a lot of use cases for EPD [3]. This research presents the integration of a flexible EPD to an Elster AS300P smart meter and studies the pros and cons of using this technology for smart metering.

\subsection{Electrophoretic displays}

EPDs are based on a phenomenon called electrophoresis, which is movement of electrically charged molecules or particles under influence of an electric field [4]. The operation theory of EPDs is shown in Fig.1 Most of the EPDs today, use a two-particle dispersion, black and white pigment particles in a microencapsulated and electrically insulating oil. The microcapsules are placed between a single transparent electrode and a pattern of electrodes at the bottom plate.

The dark pigment is normally a negatively charged carbon black material, while the white pigments are positively charged Titanium Dioxide (TiO2) nanoparticles [4]. When a DCvoltage is applied over the two electrodes, the white and black particles are driven to opposite faces that forms the pixel on the display. 


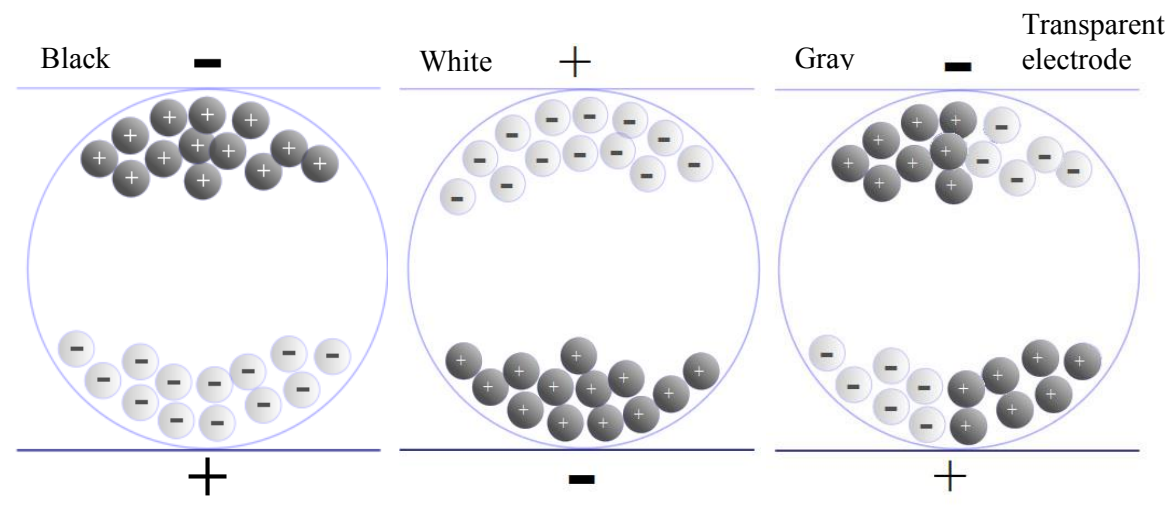

Fig. 1. EPD pixel states [4]

\subsection{Electrophoretic displays vs. Liquid crystal displays in smart meters}

The comparison between EPD and liquid crystal displays (LCD) in smart meters is summarized in the below table[5, 6]:

Table 1. EPD vs. LCD

\begin{tabular}{|c|c|c|c|}
\hline & EPD & LCD & Comments \\
\hline $\begin{array}{l}\text { Power } \\
\text { consumption }\end{array}$ & $\begin{array}{l}\text { Once the image is } \\
\text { formed there is no } \\
\text { more power } \\
\text { consumption }\end{array}$ & $\begin{array}{l}\text { There needs to be } \\
\text { an image update } \\
\text { each } 20 \mathrm{~ms} \text { to avoid } \\
\text { flicker }\end{array}$ & $\begin{array}{l}\text { Taking into } \\
\text { consideration that the } \\
\text { meters are powered for } \\
\text { their entire lifetime } \\
(10 \mathrm{yr} \text { to } 20 \mathrm{yr}) \\
\text { important power saving } \\
\text { can be achieved with } \\
\text { EPD }\end{array}$ \\
\hline Price & $\begin{array}{l}\text { More expensive than } \\
\text { LCD due to higher } \\
\text { component count } \\
\text { needed to operate the } \\
\text { display }\end{array}$ & $\begin{array}{l}\text { This technology is } \\
\text { by far the most } \\
\text { widespread in } \\
\text { smart metering } \\
\text { thus the cheapest }\end{array}$ & $\begin{array}{l}\text { LCD technology is } \\
\text { cheaper by itself but for } \\
\text { the overall cost for } \\
\text { some applications such } \\
\text { as read without power } \\
\text { is lower for EPD } \\
\text { displays }\end{array}$ \\
\hline Image retention & $\begin{array}{l}\text { Image retention is one } \\
\text { of the main } \\
\text { advantages over EPD }\end{array}$ & $\begin{array}{l}\text { LCD displays have } \\
\text { no image retention }\end{array}$ & \\
\hline $\begin{array}{l}\text { Temperature } \\
\text { behaviour }\end{array}$ & $\begin{array}{l}\text { EPD displays have } \\
\text { latency and image } \\
\text { ghosting at negative } \\
\text { temperatures }\end{array}$ & $\begin{array}{l}\text { Good negative } \\
\text { temperature } \\
\text { behaviour }\end{array}$ & \\
\hline $\begin{array}{l}\text { Implementation } \\
\text { complexity }\end{array}$ & $\begin{array}{l}\text { The display driver } \\
\text { together with the } \\
\text { power supply } \\
\text { requirements are quite } \\
\text { complex }\end{array}$ & Easy to implement & $\begin{array}{l}\text { LCD technology by } \\
\text { itself is easier to } \\
\text { implement however } \\
\text { depending on the } \\
\text { application it might be } \\
\text { the other way around }\end{array}$ \\
\hline Viewing angle & $\begin{array}{l}\text { The viewing angle is } \\
\text { better than LCD }\end{array}$ & $\begin{array}{l}\text { High viewing angle } \\
\text { increases prices of } \\
\text { LCD }\end{array}$ & $\begin{array}{l}\text { EPD technology offers } \\
\text { better viewing angle }\end{array}$ \\
\hline
\end{tabular}




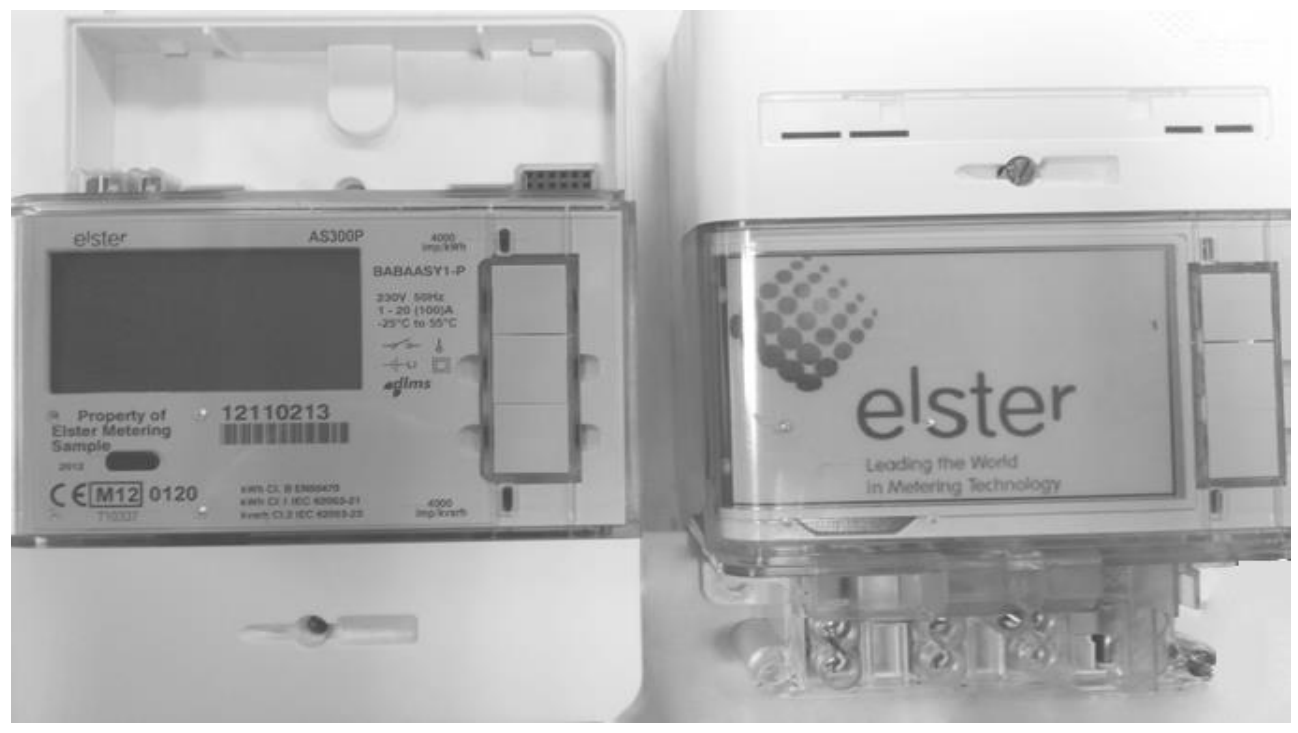

Fig.2 Meter with LCD vs EPD

\section{EPD MODULE DESIGN}

\subsection{Hardware Architecture of the EPD module}

The purpose of this diagram is to give a general overview of the main hardware components and the communication protocols used by them. On the PCB the power supply is also present.

For development purposes the module is prepared to accommodate a $\mu \mathrm{SD}$ card because the internal memory of the TI MSP430 $\mu \mathrm{C}$ is too small for generating and storing more than one image. MSP430F5438AIPZ has 256kB of flash memory and one .pgm image for this display has $94 \mathrm{kB}$.

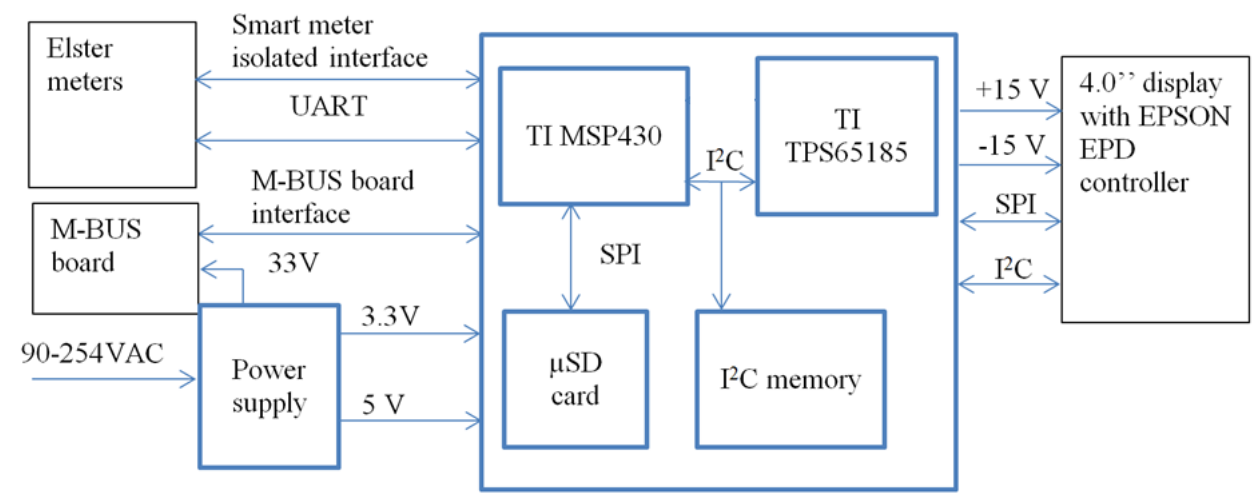

Fig. 3. Block diagram of the EPD module 
The EPD module design is based on the Plastic Logic reference design Parrot mainboard together with Hummingbird Z6 display driver board.

\subsection{Firmware architecture}

The Firmware was developed starting from the source code provided freely by Plastic Logic [7] and it is comprised out of 3 layers:

Application Layer is on top of the common components. There is no layer that abstracts a complete display system that can be manipulated by calling methods on it. The components of the application layer are: File Allocation Table file system (FatFs) is a generic module for small embedded systems, Epson is handling the display driver, and digital to analog converter (DAC), Electrically Erasable Programmable Read-Only Memory (EEPROM) is used to store specific calibration data such as the common cathode voltage level value, power management integrated circuit (PMIC) is used to generate the voltage levels needed to drive the EPD.

Access Abstraction Layer is needed due to the Epson display controller which has resources such as Inter-Integrated Circuit communication protocol (I2C), Serial Peripheral Interface (SPI), and General-Purpose input/output (GPIO) that the Application layer may want to use. This abstraction layer allows the application to access either a host microcontroller resource or one contained in the Epson display controller without needing to know where it is based.

Host Abstraction Layer allows for porting the code to different microcontrollers, sharing the same architecture or not.

Application

PMIC EEPROM DAC EPSON FAT-FS TEMP

\begin{tabular}{llll}
\hline \multicolumn{4}{l}{ Access } \\
I2C & SPI & GPIO \\
\hline
\end{tabular}

Host Abstraction Layer

I2C SPI-EPSON GPIO SPI SD Interrupts Timers

Fig. 4. Block diagram of the Firmware Architecture 


\section{Experimental Results}

For validating the design, we have conducted a series of temperature variation tests using the climatic chamber. The temperature range for Plastic Logic EPD is determined by the media used, which consists of microcapsules filled with a clear fluid. Low temperatures raise the viscosity of this fluid typically resulting in a slower response time for image updates therefore the manufacturer states operation at a minimum of $0^{\circ} \mathrm{C}$. However, the meter self-heating (due to internal power dissipation) enables the meter with EPD to operate also at negative temperatures. For evaluating the performance of the display, we have used two images, one when the meter is in run mode and the other when the meter goes into power fail, in the following sections only the image when the meter goes into power-fail will be shown.

\subsection{EPD meter behaviour at $0^{\circ} \mathrm{C}$}

Test results at $0^{\circ} \mathrm{C}$ show that the refresh rate and shadow image is not visible. In case of power fail the image is formed on the display without "ghosting" and contrast loss.

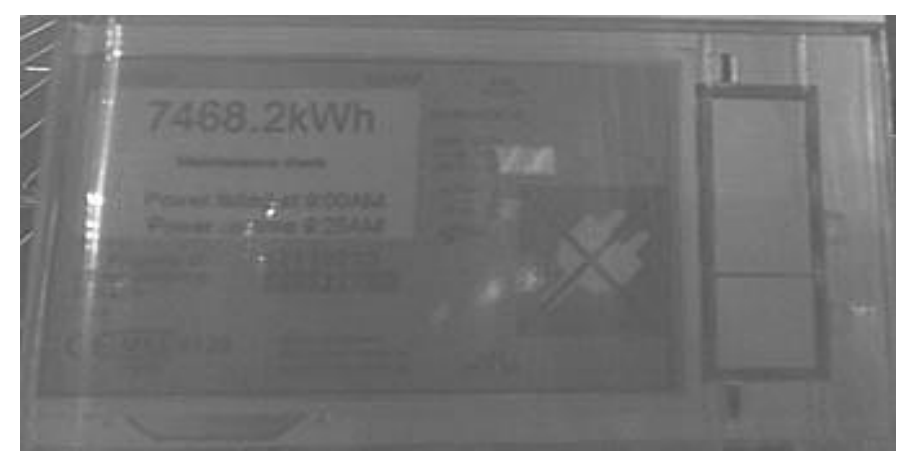

Fig. 5. EPD meter at $0^{\circ} \mathrm{C}$

\subsection{EPD meter behaviour at $-10^{\circ} \mathrm{C}$}

Test results at $-10^{\circ} \mathrm{C}$ show that the refresh rate is not affected and the shadow image is partially visible. In case of power fail the image is formed on the display with a low contrast "ghost" image. 


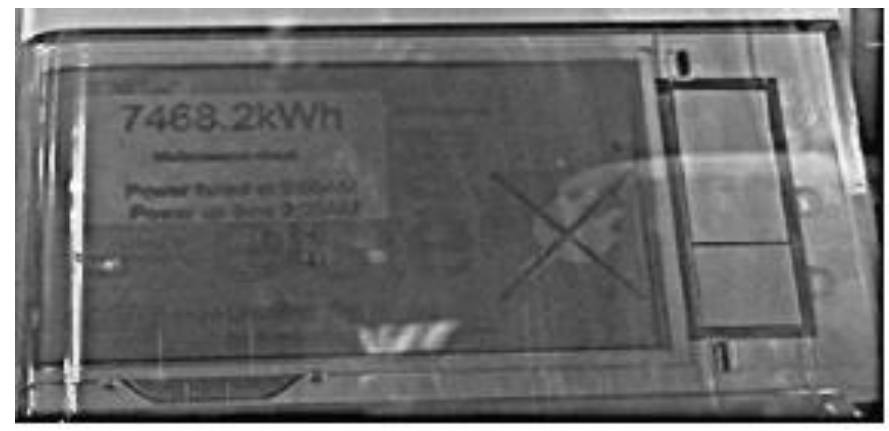

Fig. 6. $\mathrm{EPD}$ meter at $-10^{\circ} \mathrm{C}$

\subsection{EPD meter behaviour at $-25^{\circ} \mathrm{C}$}

Test results at $-25^{\circ} \mathrm{C}$ show that the refresh rate is affected and the shadow image is visible. In case of power fail the image is formed on the display has a high contrast "ghost" image.

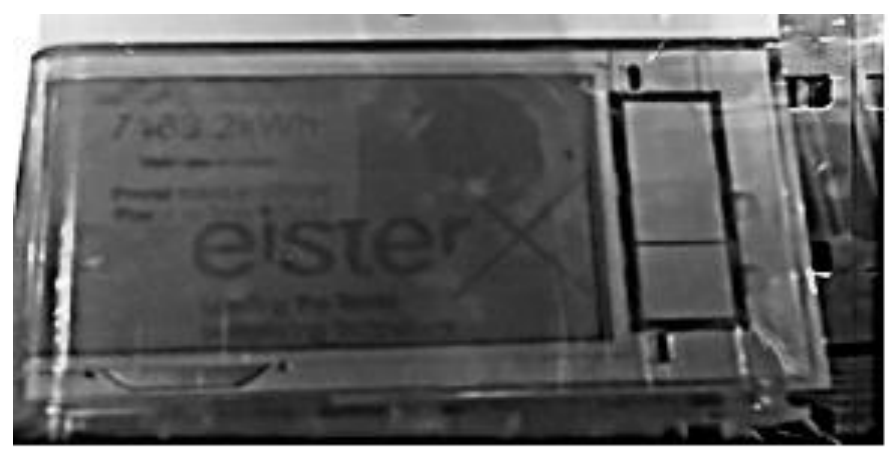

Fig. 7. $\mathrm{EPD}$ meter at $-25^{\circ} \mathrm{C}$

\section{Conclusion}

This paper presents the integration of an EPD display on a smart meter and analyses the advantages and disadvantages of using the technology for smart meters.

EPD technology main benefit is image retention which makes it a possible solution for read without power feature in smart meters which eliminates the need of a backup power supply (typically battery or supercapacitor) also power savings can be achieved in comparison with LCD because there is no need to refresh the image each $20 \mathrm{~ms}$. At this moment temperature behaviour and implementation cost are the main drawbacks of this technology. 


\section{References}

1. A.L. Dalisa, Electrophoretic Display Technology, IEEE Tran. On El. Dev., 24 (1977)

2. I. Ota, J. Ohnishi, M. Yoshiyama, Electrophoretic image display (EPID) panel, Proc. IEEE, 61(1973)

3. Software Guide. Display Evaluation Kit K_MSP430, retrieved from http://www.plasticlogic.com/wp-

content/uploads/SoftwareGuide_K_MSP430_303002_303004_303006_303010_1.pdf last accessed on 15 June 2018

4. Electronic Paper, available at https://en.wikipedia.org/wiki/Electronic_paper, last accessed on 15 June 2018

5. M. R. Fernández, E. Z. Casanova, I. G. Alonso, Review of Display Technologies Focusing on Power Consumption, Sustainability 2015, 7, Online available at : https://core.ac.uk/download/pdf/75991139.pdf, last accessed on 2 April 2019

6. Franky So, Organic Electronics: Organic Electronics: Materials, Processing, Devices and Applications, pp395, CRC Press, 24 Nov. 2009, Online available at : https://books.google.ro/books?id=iGXIfu4cqZYC\&pg=PA393\&lpg=PA394\&focus=vi ewport\&dq $=\mathrm{EPD}+\mathrm{vs}+\mathrm{LCD} \& \mathrm{hl}=\mathrm{ro} \# \mathrm{v}=$ onepage $\& \mathrm{q}=\mathrm{EPD} \% 20 \mathrm{vs} \% 20 \mathrm{LCD} \& \mathrm{f}=$ false, last accessed on 2 April 2019

7. Software Guide. Display Evaluation Kit K_MSP430, retrieved from http://www.plasticlogic.com/wp-

content/uploads/SoftwareGuide_K_MSP430_303002_303004_303006_303010_1.pdf last accessed on 15 June 2018 